\author{
Professor Hahn Shik LEE, PhD \\ E-mail: hahnlee@sogang.ar.kr \\ Department of Economics \\ Sogang University, Seoul, Korea \\ Woo Suk LEE, PhD Candidate \\ E-mail: woosukone@gmail.com \\ Department of Economics \\ Sogang University, Seoul, Korea
}

\title{
INTERNATIONAL LINKAGE AMONG MENA FINANCIAL MARKETS
}

Abstract. Despite the increasing interest on the topic of international transmission of financial markets, the MENA region has received little attention concerning linkage among financial markets. In fact, the MENA's level of connectedness has declined during the last two decades. This paper investigates international linkage among the MENA financial markets by estimating the magnitudes and dynamics of connectedness measures across various combinations of markets and countries, in relation to US and Euro financial markets. The basic finding is that the connectedness among MENA countries seems rather weak, while US markets are an important source of network effects on financial markets in this region. Among the MENA countries, the Turkish markets show relatively high connectedness with advanced financial markets. We also observe time-varying patterns in the connectedness indices, with a surge during the global financial crisis. The observation suggests that new shocks occurred in one market can spread to other markets in different degrees, hence we need to assess the connectedness dynamics as well as the average connectedness.

Keywords: MENA financial markets, Connectedness index, Spillover effect.

\section{JEL Classification: G15, F65, C32.}

\section{Introduction}

With the developments in the liberalization of capital movements and worldwide network processing of news, international financial markets have become increasingly interdependent. Repeated financial market turmoil, such as the stock market crash of 1987, the 1997-1998 Asian financial crisis, the global financial crisis (GFC, hereafter), and the European debt crisis (EDC, hereafter), have also contributed to good episodes of the spillover effect. As a consequence, an increasing attention has been given in recent literature to the topic of international linkage among financial markets.

Using international stock return data, previous studies generally found evidence for spillover effects across international stock markets. Eun and Shim

DOI: 10.24818/18423264/53.3.19.17 
(1989) documented that news originating in the US market brings the most influential responses from other national markets. Other studies concerning the international transmissions of financial markets presented new evidence on international linkages around the globe. For instance, Booth et al. (1997) provided evidence for price and volatility spillovers among the Scandinavian countries. Lee and Hong (2009) found significant spillovers among the Asian countries. As for the relationship between advanced and emerging countries, Lee (2004) presented evidence that emerging Asian countries are subject to the influences from the US stock market.

While new observations on international linkages have widely been discussed around the globe, the Middle East and North African (MENA) region has received little attention. In fact, several studies discussed connectedness of the MENA region. For example, Yu and Hassan (2008) discussed the transmission mechanism of stock returns and volatility among the MENA and world markets. Lee (2010) presented evidence on international linkages among the major developed markets (US, Japan and Germany) and emerging markets in the MENA region (Turkey and Egypt). Eissa et al. (2010) discussed volatility spillovers among MENA stock and exchange markets. Maghyereh et al. (2015) presented new observations on dynamic transmissions between US and MENA equity markets. Ozturk and Volkan (2015) suggested that the MENA financial markets are still globally segmented, although inter-MENA links among the GCC countries seem strong. Neaime (2016) considered the effects of financial crises on connectedness among emerging MENA stock markets. ${ }^{1}$

Although quite a few attempts have been made in recent literature to discuss the connectedness in the MENA region, most of these papers have focused on stock markets. In fact, some of earlier paper have used weekly data to examine spillover effects among financial markets. In view of the recent development in information network that is capable of disseminating news instantaneously around the world, shocks in a national stock market can be transmitted to other markets within a very short period of time. Hence, it is essential to use high-frequency data such as daily prices to investigate connectedness among financial markets.

The main purpose of this paper is to investigate whether the MENA financial markets are connected to each other. We also examine to what extent the MENA region is integrated globally with major developed financial markets. In particular, we estimate connectedness measures across different asset-class (stock, foreign exchange) markets for Egypt, Morocco, Qatar, Saudi Arabia and Turkey. We also discuss the magnitude, direction, and dynamics of the connectedness across various combinations of markets and countries, in relation to the US and Euro financial markets.

\footnotetext{
${ }^{1}$ Given the increasing attention on the MENA financial markets, Pacific-Basin Finance Journal published special issues on Islamic banking and finance (Ibrahim and Mirakhor, 2014; Ibrahim, 2015).
} 
Although the MENA region has played an increasing role in cross-border financial flows, this study indicates that the connectedness among MENA countries still remains rather weak. This result is consistent with recent observation that most countries in the MENA region display low levels of connectedness in the MGI index. ${ }^{2}$ As for the dynamic aspects of connectedness, we observe time-varying patterns in connectedness measures, with a surge around the GFC.

The paper is organized as follows. Section 2 introduces the connectedness approach employed in this study, and section 3describes basic characteristics of the data. In section 4 , we investigate the connectedness relationships among the MENA financial markets, and discuss their implications. Section 5 provides a summary with brief discussions.

\section{Empirical Methodology}

There has been considerable literature on international linkages among financial markets. Using the connectedness framework via variance decomposition of VAR model, Diebold and Yilmaz (2012) developed a powerful empirical approach to analyzing spillover effects. Diebold and Yilmaz (2016) investigated the connectedness among US and European financial institutions by employing the network methodology.

The connectedness approach is particularly useful, as it is a unified framework for conceptualizing and empirically measuring the network connectedness at a variety of levels, from pair-wise to system-wide relationships. Hence, many authors have employed this methodology in investigating cross-country connectedness among stock markets (Tsai, 2014; Diebold and Yilmaz, 2015), bond markets (Antonakakis and Vergos, 2013), foreign exchange markets (Antonakakis, 2012; Chang, 2013), and housing markets (Liow, 2014; Lee and Lee, 2018).

We briefly describe the connectedness methodology. Consider a covariance stationary m-variable $\operatorname{VAR}(p)$ process written as:

$$
X_{t}=\sum_{i=1}^{p} \Phi_{i} X_{t-i}+\varepsilon_{t} \text { with } \varepsilon_{t} \sim \operatorname{iid}(0, \Sigma) .
$$

This VAR system can be rewritten as a moving average representation, given by

$X_{t}=\sum_{i=0}^{\infty} A_{i} \varepsilon_{t-i}$.

To measure connectedness, we use the generalized approach, as discussed in Diebold and Yilmaz (2012), which is not sensitive to the variable ordering. The $H$-step-ahead forecast error variance decomposition can be computed as follows:

$$
\theta_{i j}(H)=\frac{\sigma_{j j}^{-1} \sum_{h=0}^{H-1}\left(e_{i}^{\prime} A_{h} \sum e_{j}\right)^{2}}{\sum_{h=0}^{H-1}\left(e_{i}^{\prime} A_{h} \sum A_{h}^{\prime} e_{i}\right)},
$$

where $\sum$ is the variance matrix for the error vector $\varepsilon_{t}, \sigma_{j j}$ is the standard deviation of $\varepsilon_{j t}$, and $e_{i}$ is the selection vector with $i$-th element unity and zero otherwise. As $\sum_{j=1}^{m} \theta_{i j}(H) \neq 1$, we normalize each entry by the row sum:

$$
\tilde{\theta}_{i j}(H)=\frac{\theta_{i j}(H)}{\sum_{j=1}^{m} \theta_{i j}(H)},
$$

\footnotetext{
${ }^{2}$ See Manyika and Lund (2014) and McKinsey Global Institute (2016).
}

DOI: 10.24818/18423264/53.3.19.17 
so that we have $\sum_{j=1}^{m} \tilde{\theta}_{i j}(H)=1$ and $\sum_{i, j=1}^{m} \tilde{\theta}_{i j}(H)=m$.

Equation (4) represents a pairwise directional connectedness $\tilde{\theta}_{i j}$, from market $j$ to market $i$ at horizon $H$, which can be used to derive various connectedness measures. By denoting $\tilde{\theta}_{i j}$ as $C_{i \leftarrow j}$, we can explicitly indicate the direction of connectedness, and the net pairwise directional connectedness can be defined as:

$$
C_{i j}(H)=C_{i \leftarrow j}(H)-C_{j \leftarrow i}(H)
$$

We are also interested in the total directional connectedness, which can be defined in two directions. The total directional connectedness indices "from others (to $i$ )" and "to others (from $i$ )" can be derived from off-diagonal row sum and column sum, respectively:

$$
C_{i \leftarrow \bullet}(H)=\sum_{\substack{j=1 \\ j \neq i}}^{m} \tilde{\theta}_{i j}(H) \text { and } C_{\bullet \leftarrow i}(H)=\sum_{\substack{j=1 \\ j \neq i}}^{m} \tilde{\theta}_{j i}(H) .
$$

Similarly to equation (5), we may be interested in the net total directional connectedness, which is defined as the difference between "to" and "from" others:

$$
C_{i}(H)=C_{\bullet \leftarrow i}(H)-C_{i \leftarrow \bullet}(H)
$$

Finally, the total connectedness is the ratio of the sum of the off-diagonal elements of the variance decomposition matrix to the sum of all its elements:

$$
C(H)=\frac{\sum_{i, j=1}^{m} \widetilde{\theta}_{i j}(H)}{\sum_{i, j=1}^{m} \widetilde{\theta}_{i j}(H)}=\frac{\sum_{\substack{i, j=1 \\ i \neq j}}^{m} \widetilde{\theta}_{i j}(H)}{m}
$$

\section{Data and Descriptive Statistics}

In this study, we employ daily indices of major financial markets in the MENA region (Egypt, Morocco, Qatar, Saudi Arabia and Turkey). ${ }^{3}$ The sample period ranges from January 2002 to June 2017. We collected the data set for the MENA financial markets from the Datastream, while they are also available from official websites of each countries. In particular, we use the daily returns on the MENA financial markets together with those on the US and Euro markets. The stock market indices are EGX 30 (Egypt), MADE (Morocco), QSE (Qatar), TASI (Saudi Arabia), and BIST National 100 (Turkey) for the MENA region, and S\&P 500 Index (US), and Euro STOXX 50 (Euro) for advanced countries. As for the foreign exchange market, the local currencies per US dollar are used. Although the US dollar plays the role of the base currency for other countries, we use the US

\footnotetext{
${ }^{3}$ Among the countries in MENA region, Egypt, Morocco, Qatar, Saudi Arabia and Turkey are considered in this paper, as other countries such as Bahrain, Oman, Kuwait, and UAE impose barriers and restrictions on foreign investments in domestic equities, preventing deeper capital market integration. For example, Amman Stock Exchange imposed a ceiling of 50\% foreign ownership for companies operating in some specific sectors. Foreign investors are allowed to own a maximum of $49 \%$ of UAE corporations, and foreign ownership in Omani companies is generally limited to $70 \%$. Note also that we include only the stock and foreign exchange markets in this paper. Although markets for government bonds, corporate bonds and Sukuk have recently been growing very fast, most of the bond market data in this region are unavailable and/or quite limited, and the bond market is not considered in this study.
} 
International Linkage among MENA Financial Markets

dollar index as the US foreign exchange market data. Table 1 summarizes the basic data description.

Table 1.Data description

\begin{tabular}{lll}
\hline \multicolumn{1}{c}{ Country } & \multicolumn{1}{c}{ Stock market } & \multicolumn{1}{c}{ FX market } \\
\hline US & Standard and Poor's 500(S\&P500) & US dollar index \\
Euro & Euro STOXX 50 & Euro to US Dollar \\
Turkey & Borsa İstanbul National 100(BIST National 100) & Turkish Lirato US Dollar \\
Egypt & Egyptian Exchange 30(EGX 30) & Egyptian Pound to US Dollar \\
Qatar & Qatar Stock Exchange(QSE) & Qatari Riyalto US Dollar \\
Morocco & Moroccan Most Active Shares Index(MADE) & Moroccan Dirham to US Dollar \\
SaudiArabia & Tadawul All Share Index (TASI) & Saudi Riyal to US Dollar \\
\hline
\end{tabular}

Figure 1 shows time series plots for financial market indices of these countries. We can observe a few distinctive features in the movements of both the stock and FX markets. First, the stock markets displayed upward trends on average, with a dramatic fall around the bankruptcy of Lehman Brothers in September 2008, although they showed different patterns of fluctuations. We can also observe noticeable downturns, in particular, in the Egyptian and Qatari stock markets during 2015, which might be caused by oil price slump.

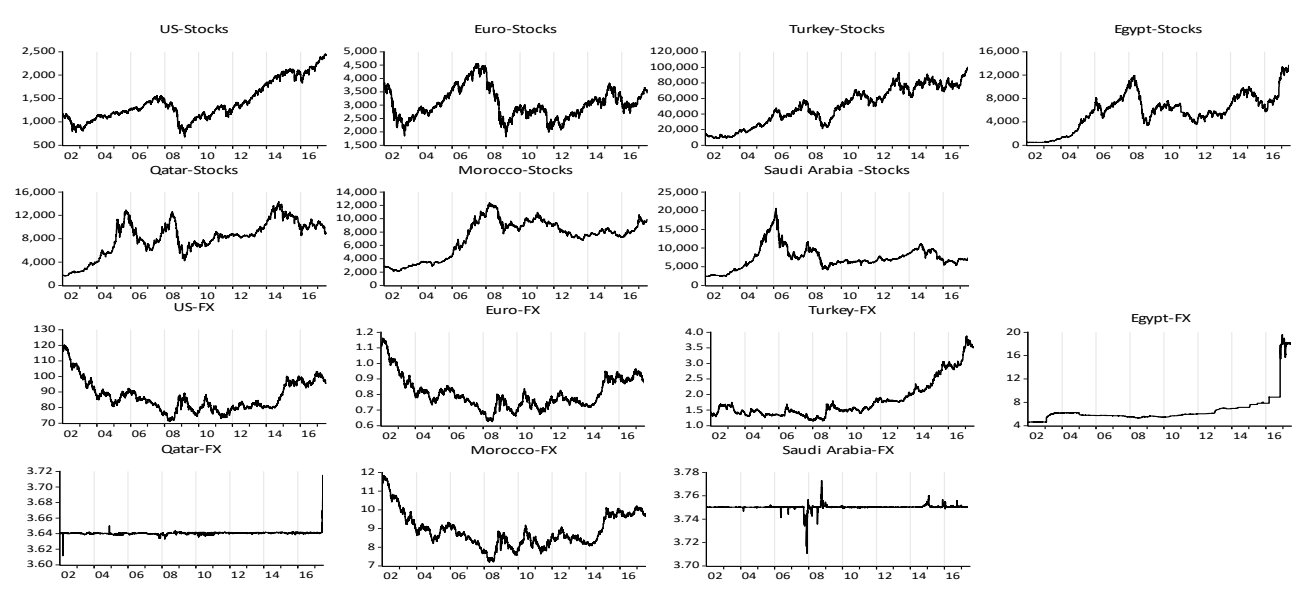

Figure 1.Time series plots of financial market indices

Notes: These plots display time variations of 14 financial market indices from January 2, 2002 to June 30, 2017. We can notice that the FX markets in Qatar and Saudi Arabia reflect de facto fixed exchange rate regime, and that the Egyptian market moved to floating regime since November 2016.

Second, the foreign exchange markets show different features across different countries, due to different exchange rate regimes for each countries. Egypt maintained de facto fixed exchange rate regimes until a floating system was introduced on November 2016, in response to the IMF bail-out precondition. Qatar and Saudi Arabia adopted de facto fixed exchange rate regimes, which led to an almost constant level of exchange rates during the sample period. Morocco

DOI: 10.24818/18423264/53.3.19.17 
maintained fixed-peg regimes with respect to both Euro and US dollar. As Moroccan dirham's exchange rate was fixed via a peg with $80 \%$ weight to Euro and $20 \%$ to US dollar, prior to April 2015, it displays very similar fluctuations to Euro. ${ }^{4}$ In contrast, Turkey has adopted free floating exchange rate regime since February 2001, and the lira currency shows a rapidly increasing trend.

Table 2 reports the summary statistics for return series. It appears that volatilities of stock markets are higher than those of FX markets. Also note that FX markets for Egypt, Qatar, and Saudi Arabia show very high kurtosis statistics, which reflects the observation that these countries have mostly been on fixed exchange rate regimes.

Table 2. Summary statistics

\begin{tabular}{|c|c|c|c|c|c|c|c|}
\hline & \multicolumn{7}{|c|}{ Stocks } \\
\hline & US & Euro & Turkey & Egypt & Qatar & Morocco & Saudi Arabia \\
\hline Mean & 0.018 & -0.002 & 0.049 & 0.082 & 0.041 & 0.031 & 0.028 \\
\hline Median & 0.027 & 0.000 & 0.034 & 0.023 & 0.025 & 0.000 & 0.067 \\
\hline Std. Dev & 1.188 & 1.471 & 1.806 & 1.664 & 1.357 & 0.822 & 1.549 \\
\hline Skewness & -0.233 & -0.035 & -0.145 & -0.456 & -0.415 & 0.369 & -0.584 \\
\hline \multirow[t]{3}{*}{ Kurtosis } & 13.265 & 8.120 & 7.806 & 13.717 & 11.238 & 14.728 & 15.060 \\
\hline & \multicolumn{7}{|c|}{ FX } \\
\hline & US & Euro & Turkey & Egypt & Qatar & Morocco & Saudi Arabia \\
\hline Mean & -0.005 & -0.006 & 0.022 & 0.034 & 0.000 & -0.004 & 0.000 \\
\hline Median & 0.000 & 0.000 & -0.005 & 0.000 & 0.000 & -0.001 & 0.000 \\
\hline Std. Dev & 0.510 & 0.611 & 0.820 & 0.863 & 0.035 & 0.484 & 0.025 \\
\hline Skewness & -0.059 & -0.087 & 0.003 & 34.595 & -4.114 & -0.075 & 2.588 \\
\hline Kurtosis & 4.742 & 5.780 & 19.023 & 1605.774 & 391.922 & 6.148 & 200.057 \\
\hline
\end{tabular}

\section{Empirical Results}

In this section, we first estimate full-sample connectedness among 10 financial markets in the MENA region in order examine basic features of connectedness. Next, we include the US and Euro financial markets in the VAR model, as they are known to play a major source of shocks in the global financial markets. The rolling-sample estimation is also employed to assess the time-varying aspects of connectedness measures.

\subsection{Full-sample Analysis}

Table 3 presents the estimation results on connectedness measures for 10 financial markets in the MENA region. The results are based on a VAR of order 1, selected by Schwarz information criterion, and a forecast horizon of 10 days is used to calculate variance decompositions. The connectedness table provides an approximate 'input-output' decomposition of the total connectedness measures,

${ }^{4}$ Moroccan dirham is currently fixed via a peg with $60 \%$ weight to Euro and $40 \%$ to US dollar. Morocco's central bank introduced a more flexible exchange rate system (widening the currency fluctuation bands to $\pm 2.5 \%$ ) in January 13, 2018 . 
International Linkage among MENA Financial Markets

and enables us to assess various features of the financial market connectedness. Its main 10x10 block contains the variance decompositions. From a connectedness perspective, diagonal elements measure own connectedness, while off-diagonal elements, $C_{i \leftarrow j}(H)$, measure pairwise directional connectedness. Similarly to the pairwise directional connectedness, we are particularly interested in net total effects. We define the net total directional connectedness as a difference between the sum of 'to' column and 'from' row except the diagonal elements. Finally, the grand off-diagonal column sum (or row sum) relative to the sum of all elements can be used as a measure of total connectedness.

Table 3. Full sample connectedness table (MENA region)

\begin{tabular}{|c|c|c|c|c|c|c|c|c|c|c|c|c|}
\hline & \multicolumn{5}{|c|}{ Stocks } & \multicolumn{5}{|c|}{ FX } & \multirow[b]{2}{*}{ From } \\
\hline & & TR & $\mathrm{EG}$ & QA & MA & SA & TR & EG & QA & MA & SA & \\
\hline \multirow{5}{*}{$\frac{\infty}{\overrightarrow{0}}$} & Turkey & 78.8 & 1.8 & 0.9 & 0.3 & 1.4 & 15.2 & 0.0 & 0.0 & 1.4 & 0.2 & 21.2 \\
\hline & Egypt & 3.2 & 83.9 & 3.6 & 0.6 & 4.1 & 3.0 & 0.8 & 0.0 & 0.6 & 0.1 & 16.1 \\
\hline & Qatar & 1.5 & 4.2 & 81.5 & 0.5 & 7.6 & 3.1 & 0.0 & 0.0 & 1.1 & 0.4 & 18.5 \\
\hline & Morocco & 0.2 & 0.9 & 0.3 & 97.4 & 0.8 & 0.3 & 0.1 & 0.0 & 0.1 & 0.0 & 2.6 \\
\hline & Saudi Arabia & 1.7 & 2.8 & 3.4 & 0.3 & 88.8 & 2.5 & 0.0 & 0.1 & 0.2 & 0.2 & 11.2 \\
\hline \multirow{5}{*}{$\vec{x}$} & Turkey & 16.8 & 2.0 & 1.9 & 0.2 & 1.7 & 71.8 & 0.0 & 0.0 & 5.5 & 0.1 & 28.2 \\
\hline & Egypt & 0.0 & 0.2 & 0.0 & 0.1 & 0.0 & 0.1 & 99.6 & 0.0 & 0.0 & 0.0 & 0.4 \\
\hline & Qatar & 0.1 & 0.0 & 0.0 & 0.0 & 0.1 & 0.0 & 0.0 & 99.4 & 0.0 & 0.3 & 0.6 \\
\hline & Morocco & 1.6 & 0.2 & 0.3 & 0.1 & 0.2 & 4.4 & 0.0 & 0.0 & 93.1 & 0.0 & 6.9 \\
\hline & Saudi Arabia & 0.1 & 0.2 & 0.3 & 0.0 & 0.2 & 0.1 & 0.0 & 0.3 & 0.1 & 98.8 & 1.2 \\
\hline \multirow{2}{*}{\multicolumn{2}{|c|}{$\begin{array}{c}\text { To } \\
\text { Net }\end{array}$}} & 25.1 & 12.2 & 10.6 & 2.1 & 16.1 & 28.7 & 1.0 & 0.4 & 9.1 & 1.5 & 106.7 \\
\hline & & 3.9 & -3.9 & -7.8 & -0.5 & 4.8 & 0.6 & 0.6 & -0.2 & 2.2 & 0.3 & 10.7 \\
\hline
\end{tabular}

As for the stock markets, Morocco shows the highest own-connectedness (97.4\%), indicating that only $2.6 \%$ of its variation is affected from shocks in other countries and/or other asset-class markets. The largest pairwise connectedness for the Moroccan stock market is $0.9 \%$ with the Egyptian stock market. On the other hand, own-connectedness measures of stock markets in Turkey and Qatar are around $80 \%$, indicating a relatively high connectedness to other markets. In particular, the connectedness measures between Saudi and Qatari stock markets are higher than other connectedness among the MENA stock markets $(7.6 \%$ and $3.4 \%$ ). This observation might somewhat be expected from their geographical proximity. The Egyptian and Qatari stock markets also show relatively high connectedness indices $(4.2 \%$ and $3.6 \%)$. While the Turkish stock market shows the smallest own-connectedness $(78.8 \%)$, which may indicate more connectedness to other markets, it turns out to be largely connected to its own FX market (16.8\% and $15.2 \%)$.

A little different picture emerges for the foreign exchange markets. In this case, Egypt and Qatar show highest own-connectedness measures (99.6\% and $99.4 \%$ ), whereas only $0.4 \sim 0.6 \%$ is from shocks in other countries and/or asset-class markets. These results reflect the observation that Egypt and Qatar maintained de

DOI: 10.24818/18423264/53.3.19.17 
facto fixed exchange rate regimes during most of the sample period. Although Saudi Arabia also adopted a fixed exchange rate regime, Saudi riyal displays more fluctuations than Egyptian pound and Qatari riyal, which may lead to a lower ownconnectedness. Note also that Morocco adopts fixed-peg regime with respect to both Euro and US dollar. As we use Moroccan dirham's exchange rate to US dollar, it appears to have more connectedness to other financial markets in the MENA region. In particular, its connectedness to Turkish lira turns out to be highest among the MENA financial markets (5.5\% and 4.4\%).

In order to obtain some insights into the degrees of connectedness among the MENA financial markets, we calculate the total connectedness as a single index. The estimated total connectedness is $10.7 \%$, as presented on lower right corner in Table 3, which is derived as the sum of the 'from' column (or 'to' row) relative to the grand column sum including diagonals. This indicates that $89.3 \%$ of the variations are due to idiosyncratic shocks. Overall, the connectedness among the ten financial markets is quite low.

Next, we include the US financial markets in the VAR model, as they are known to play a major source of shocks in the global financial market. In order to examine the connectedness of the MENA region to other advanced countries, the Euro financial markets are also included in this study. Table 4 presents the estimation results on connectedness measures for the 14 financial markets in both the MENA region and advance countries. The results are also based on a VAR (1), and a forecast horizon of 10 days is used to calculate variance decompositions. Now we have a connectedness table consisting of $14 \times 14$ block from the variance decompositions. $^{5}$

As for the connectedness of US with the MENA region, the US stock market has positive net pairwise connectedness measures vis-à-vis all other stock markets. In particular, the US stock market shows the highest net connectedness $22.2 \%(61.1 \%$ - 38.9\%).In fact, stock markets in US (22.2\%) and EURO (7.0\%) have been the most influential affecting other financial markets in this region.Other markets are the recipients with negative net connectedness, which suggests the hierarchy among asset classes in terms of their reflections of the overall economy. ${ }^{6}$ In particular, net connectedness measures of Turkey and Qatar are negative, which implies that they are net recipients among these financial shocks. Among others, the Turkish FX market has the highest negative value, $16.2 \%$, indicating that the Turkish FX market is vulnerable to shocks from other

\footnotetext{
${ }^{5}$ For comparison, we also estimated the connectedness tables for each separate asset-class market. Although detailed estimates are a bit different from those in Tables 3 and 4, the main observations in this paper remain almost the same. These results are available from the authors upon request.

${ }^{6}$ Diebold and Yilmaz (2015) presented evidence that stock markets are most influential affecting other financial markets, while other markets (e.g., bond and FX markets) are the recipients with negative net connectedness. Lee and Lee (2017) also discussed a similar observation on the Northeast Asian financial markets.
} 
International Linkage among MENA Financial Markets

financial markets. In fact, Turkey shows the largest 'to' and 'from' connectedness measures in both the stock and FX markets among the MENA countries. 
Hahn Shik Lee, Woo Suk Lee

Table 4. Full sample connectedness table (Advanced and MENA markets)

\begin{tabular}{|c|c|c|c|c|c|c|c|c|c|c|c|c|c|c|c|c|}
\hline & \multicolumn{7}{|c|}{ Stocks } & \multicolumn{7}{|c|}{$\overline{\text { FX }}$} & \multirow[b]{2}{*}{ From } \\
\hline & & US & EU & TR & EG & QA & MA & SA & US & EU & TR & EG & QA & MA & SA & \\
\hline \multirow{7}{*}{$\begin{array}{l}\frac{\mathscr{2}}{8} \\
\frac{0}{6}\end{array}$} & US & 61.1 & 26.0 & 5.0 & 0.9 & 0.4 & 0.2 & 1.4 & 1.1 & 0.7 & 2.2 & 0.0 & 0.0 & 0.8 & 0.2 & 38.9 \\
\hline & EU & 27.7 & 57.3 & 8.0 & 0.9 & 0.6 & 0.2 & 1.4 & 0.3 & 0.3 & 2.8 & 0.0 & 0.0 & 0.4 & 0.2 & 42.7 \\
\hline & TR & 7.5 & 9.5 & 66.4 & 1.0 & 0.5 & 0.2 & 0.9 & 0.8 & 0.9 & 11.4 & 0.0 & 0.0 & 0.9 & .2 & 33.6 \\
\hline & EG & 5.5 & 2.9 & 2.4 & 78.6 & 2.5 & 0.4 & 3.3 & 0.7 & 0.4 & 1.9 & 0.8 & 0.0 & 0.5 & 0.1 & 21.4 \\
\hline & QA & 4.5 & 2.5 & 0.9 & 3.2 & 77.1 & 0.4 & 6.7 & 0.9 & 0.7 & 2.0 & 0.0 & 0.0 & 0.8 & 0.4 & 22.9 \\
\hline & MA & 1.5 & 0.6 & 0.1 & 0.6 & 0.1 & 95.9 & 0.6 & 0.1 & 0.1 & 0.2 & 0.1 & 0.0 & 0.1 & 0.1 & 4.1 \\
\hline & SA & 3.9 & 2.4 & 1.2 & 2.1 & 2.6 & 0.2 & 85.2 & 0.3 & 0.1 & 1.7 & 0.0 & 0.1 & 0.1 & 0.3 & 14.8 \\
\hline \multirow{7}{*}{$\vec{x}$} & US & 1.0 & 0.2 & 0.3 & 0.0 & 0.0 & 0.0 & 0.0 & 42.7 & 28.0 & 0.9 & 0.0 & 0.0 & 26.9 & 0.0 & 57.3 \\
\hline & EU & 0.7 & 0.2 & 0.4 & 0.0 & 0.0 & 0.0 & 0.1 & 26.0 & 36.5 & 1.0 & 0.0 & 0.0 & 35.1 & 0.0 & 63.6 \\
\hline & TR & 7.8 & 5.1 & 12.9 & 0.9 & 0.9 & 0.1 & 0.9 & 5.1 & 4.0 & 58.5 & 0.0 & 0.0 & 3.8 & 0.1 & 41.5 \\
\hline & EG & 0.0 & 0.0 & 0.0 & 0.2 & 0.0 & 0.1 & 0.0 & 0.0 & 0.0 & 0.1 & 99.6 & 0.0 & 0.0 & 0. & 0.5 \\
\hline & QA & 0.0 & 0.0 & 0.1 & 0.0 & 0.0 & 0.0 & 0.1 & 0.1 & 0.0 & 0.0 & 0.0 & 99.3 & 0.0 & 0. & 0.7 \\
\hline & MA & 0 & 0.3 & 0.5 & 0.0 & 0.0 & 0.0 & 0.1 & 25.2 & 35.4 & 1.0 & 0.0 & 0.0 & 36.7 & 0.0 & 63.3 \\
\hline & SA & 2 & 0.1 & 0.1 & 0.1 & 0.2 & 0.0 & 0.2 & 0.0 & 0.1 & 0.1 & 0.0 & 0.3 & 0.1 & 98.5 & 1.5 \\
\hline \multirow{2}{*}{\multicolumn{2}{|c|}{ To }} & 61.1 & 49.7 & 31.9 & 9.9 & 8.0 & 1.7 & 15.5 & 60.4 & 70.7 & 25.2 & 0.9 & 0.4 & 69.5 & 1.8 & 406.6 \\
\hline & & 22.2 & 7.0 & -1.8 & -11.5 & 14.9 & -2.3 & 0.6 & 3.0 & 7.1 & -16.2 & 0.5 & -0.3 & 6.2 & 0.3 & 29.0 \\
\hline
\end{tabular}

This observation indicates that the Turkish markets are highly connected with advanced financial markets. In this case, the largest pairwise directional connectedness among the MENA financial markets is between the Saudi and Qatari stock markets owing to their geographical proximity. The next largest pairwise directional connectedness is 3.8\% from the Moroccan FX market to the Turkish counterpart. However, this result seems due to the fact that Morocco adopts fixed-peg regime with respect to both Euro and US dollar. In fact, the connectedness of Turkish lira with Moroccan dirham is almost the same as that with the Euro (4.0\%).

As observed in Table 3, the FX markets in the MENA countries with fixed exchange rate regime (Egypt, Qatar and Saudi Arabia) show almost negligible connectedness measures with other financial markets. While Moroccan dirham appears to have higher connectedness than other FX markets in the MENA region, this results may be due mainly to its fixed-peg regime with respect to Euro and US dollar, given the observation that its connectedness measures to other markets are very similar to those of Euro currency.

As for the system-wide connectedness, we obtain a larger total connectedness index than that for the MENA region in Table $3(29.0 \%$ vs $10.7 \%)$ by incorporating the effects of US and EURO together with the MENA financial markets. However, most of the connectedness belongs to advanced markets, whereas the connectedness among the MENA financial markets seems quite low.

Although we can observe useful information from the result in Table 4, the connectedness table is not easily readable, as there are 14 financial markets in the full-sample analysis. Thus, we need to reduce the dimension of connectedness

DOI: 10.24818/18423264/53.3.19.17 
International Linkage among MENA Financial Markets

matrix by aggregating the connectedness measures at various combinations, which may provide additional information on the linkage among these financial markets.

\subsection{Cross-market and Cross-country Connectedness}

In this subsection, we further discuss various features of the connectedness in details. First, we can derive cross-market connectedness measures among financial markets by combining relevant markets across countries. Table 5 presents the cross-market connectedness tables, which can be derived by summing up crosscountry connectedness measures by regions. Note here that each asset-class markets are divided into two regions, advanced and MENA markets, by adding different numbers of markets, which is indicated as the values in parentheses in Table 5. We can first notice that advanced stock markets have been most influential affecting other financial markets (net transmitters of shocks), whereas the MENA markets are the recipients with negative net connectedness.

Table 5. Cross-market connectedness table

\begin{tabular}{|c|c|c|c|c|c|c|}
\hline & & \multicolumn{2}{|c|}{ Stocks } & \multicolumn{2}{|c|}{ FX } & \multirow[b]{2}{*}{ From } \\
\hline & & Advanced & MENA & Advanced & MENA & \\
\hline \multirow{2}{*}{ Stocks } & Advanced (2) & 172.0 & 18.9 & 2.3 & 6.8 & 28.0 \\
\hline & MENA (5) & 40.7 & 433.0 & 4.9 & 21.3 & 67.0 \\
\hline \multirow{4}{*}{ FX } & & $C_{\bullet . s \leftarrow \bullet, s}=$ & 4.7 & $C_{\bullet . s \leftarrow \bullet, x}=$ & 35.3 & \\
\hline & Advanced (2) & 2.1 & 1.0 & 133.1 & 63.9 & 66.9 \\
\hline & |MENA (5) & 14.3 & 17.3 & 69.9 & 398.6 & 101.5 \\
\hline & & \multicolumn{2}{|c|}{$C_{\cdot x \leftarrow \cdot, s}=34.7$} & \multicolumn{2}{|c|}{$C_{\cdot x \leftarrow \cdot x}=665.3$} & \\
\hline \multirow{2}{*}{\multicolumn{2}{|c|}{$\begin{array}{l}\text { To } \\
\text { Net }\end{array}$}} & 57.2 & 37.1 & 77.1 & 92.0 & \\
\hline & & 29.2 & -29.9 & 10.2 & -9.5 & \\
\hline
\end{tabular}

When we further add up regional cross-country connectedness measures, we can examine how new shocks in one asset-class market are spread to other markets as a whole. For instance, the estimated 'to' connectedness of stock markets is $34.7 \%$, while their 'from' connectedness is $35.3 \%$. Remarkably larger values of block-diagonal elements than non-diagonal ones indicate that most of the connectedness may take place within the same asset-class markets across countries. The low estimate of the net directional connectedness of stock markets, $-0.6 \%$ $(34.7 \%-35.3 \%)$, is different from the hierarchy among asset classes in terms of their reflections of the overall economy, as discussed above.

Similarly to Table 5, we can also aggregate the connectedness indices at each country level, by combining the individual measures into seven countries. The cross-country connectedness measures are presented in Table 6, which indicates that advanced countries have much larger 'to' and 'from' connectedness measures than those of the MENA countries. In particular, both US and Euro markets have positive net pairwise connectedness vis-à-vis all the MENA countries. Their net connectedness measures with MENA region are $25.5 \%(64.8 \%-39.3 \%)$ and $13.8 \%(65.0 \%-51.2 \%)$, respectively. In particular, US shows the largest positive

DOI: $10.24818 / 18423264 / 53.3 .19 .17$ 
Hahn Shik Lee, Woo Suk Lee

net pairwise connectedness, which is consistent with empirical and theoretical observations in earlier studies on this subject.

Table 6. Cross-country connectedness table

\begin{tabular}{lrrrrrrrrrr}
\hline & US & Euro & Turkey & Egypt & Qatar & Morocco Saudi Arabia & From & Advanced MENA \\
\hline US & 105.8 & 54.9 & 8.5 & 0.9 & 0.5 & 27.9 & 1.6 & 94.2 & 54.9 & 39.3 \\
Euro & 54.6 & 94.2 & 12.3 & 0.9 & 0.6 & 35.7 & 1.7 & 105.8 & 54.6 & 51.2 \\
Turkey & 21.1 & 19.4 & 149.1 & 1.9 & 1.4 & $\mathbf{5 . 0}$ & 2.0 & 50.9 & 40.5 & 10.3 \\
Egypt & 6.2 & 3.4 & 4.4 & 179.2 & 2.6 & 0.9 & 3.4 & 20.9 & 9.5 & 11.3 \\
Qatar & 5.5 & 3.3 & 3.1 & 3.2 & 176.4 & 1.2 & 7.4 & 23.6 & 8.7 & 14.9 \\
Morocco & 27.6 & 36.3 & 1.7 & 0.7 & 0.2 & 132.8 & 0.7 & 67.2 & 64.0 & 3.3 \\
Saudi Arabia & 4.4 & 2.6 & 3.0 & 2.2 & 3.2 & 0.4 & 184.1 & 15.9 & 7.1 & 8.8 \\
\hline To & 119.4 & 119.9 & 32.9 & 9.8 & 8.4 & 71.1 & 16.8 & & & \\
Advanced & 54.6 & 54.9 & 20.7 & 1.7 & 1.1 & 63.6 & 3.3 & & & \\
MENA & 64.8 & 65.0 & 12.1 & 8.1 & 7.3 & 7.5 & 13.5 & & & \\
Net & 25.3 & 14.1 & -18.0 & -11.1 & -15.2 & 3.9 & 1.0 & & & \\
$\quad$ Advanced & -0.3 & 0.3 & -19.8 & -7.8 & -7.6 & -0.3 & -3.8 & & & \\
MENA & 25.5 & $\mathbf{1 3 . 8}$ & 1.8 & -3.3 & -7.5 & 4.2 & 4.8 & & & \\
\hline
\end{tabular}

Among the MENA countries, Turkey shows the largest connectedness measures in both 'to' and 'from' directions. ${ }^{7}$ This result reflects the observation that Turkey has the largest connectedness in both the stock and FX markets among the MENA countries, as discussed in Tables 3 and 4.In particular, Turkey has the largest negative net connectedness with advanced markets, $-19.8 \%(20.7 \%-40.5 \%)$, indicating that the Turkish financial markets are highly connected with advanced countries. This observation also suggests that the Turkish markets are vulnerable to shocks from advanced financial markets. However, Turkey shows positive net pairwise connectedness indices vis-à-vis all other MENA countries, except Morocco. ${ }^{8}$ This result indicates that Turkish markets are most influential within the MENA region.

In fact, Saudi Arabia shows a larger net connectedness $(4.8 \%=13.5 \%-$ $8.8 \%)$ than Turkey $(1.8 \%=12.1 \%-10.3 \%)$ within the MENA region. However, Saudi's large net connectedness among the MENA markets seems mainly due to its nearest neighbour, Qatar. Notice here that the largest pairwise directional connectedness among the MENA countries is 7.4\% from Saudi Arabia to Qatar. This result is expected from their geographical proximity, which is also consistent with high connectedness indices obtained for their stock markets in Table 4.

The next largest pairwise directional connectedness among the MENA countries is $5.0 \%$ from Morocco to Turkey. However, this result may be due to the

\footnotetext{
${ }^{7}$ In fact, Morocco shows larger directional connectedness measures than Turkey. However, note that this result may simply reflect the fact that Morocco adopts fixed-peg regime with respect to both Euro and US dollar, which leads to high connectedness in the Moroccan FX market.

${ }^{8}$ While Morocco shows a larger net connectedness than Turkey, such a result appears to arise from its FX market, which adopts fixed-peg regime.
} 
high connectedness between their FX market, which seems to reflect the fact that Morocco adopts fixed-peg regime with respect to both Euro and US dollar, as observed in Table 4.Among the MENA countries, Qatar shows the largest negative net connectedness $(-7.5 \%)$, indicating that the Qatari financial markets are most dependent within the MENA region. Overall, the full-sample analysis suggests that advanced countries are the main source of generating connectedness in the MENA financial markets, while there is no dominant net transmitter of new shocks within the MENA region. This result suggests that the global factor plays more important role than the regional factor in affecting financial market fluctuations in this region.

\subsection{Dynamic Analysis}

The full-sample analysis in the previous subsections provides an "average" aspect of connectedness for the whole sample period. However, new shocks occurred in one market can spread other financial markets in different degrees, depending on the economic conditions. In fact, the GFC propagated across international financial markets, and hence led to several financial turmoil around the world. The advantage of dynamic analysis is to measure varying degrees of connectedness through time over business cycles. In this subsection, we provide a dynamic analysis by using 250-day rolling estimation windows with 10-day forecast horizon.

\subsubsection{Total connectedness}

Figure 2 presents the total connectedness over 250-day rolling-window samples. As expected, we can observe a time-varying pattern in the connectedness measures over the sample period. Note first that the total connectedness index has gradually increased since Lehman Brothers bankruptcy in September 2008. In particular, the index displayed a sharp peak in 2009, and showed subsequent increases during the EDC which was evolved from bailouts of Greece in May 2010. The connectedness index displayed slight rises during 2015 and 2016, with increasing uncertainties concerning increases in the US federal funds rate.

The results reveal that the connectedness across financial markets is time-

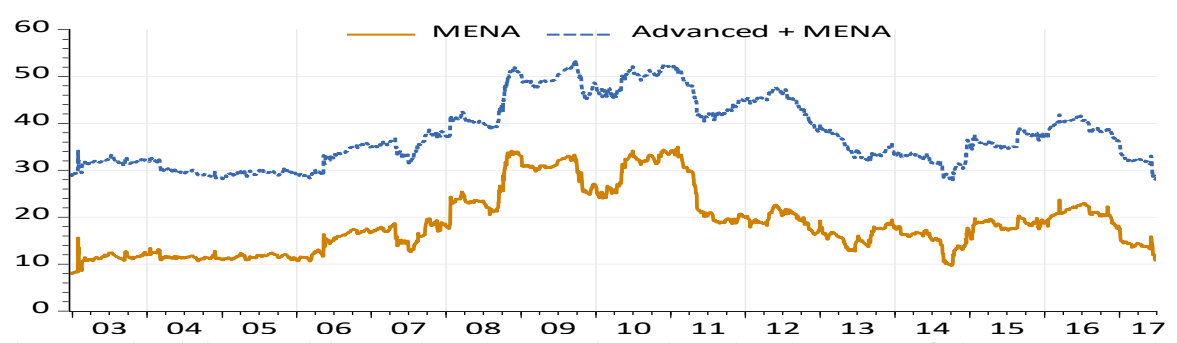

varying, and crisis sensitive. The observation that the degrees of the connectedness among financial markets are countercyclical is consistent to earlier empirical findings that negative shocks tend to have larger impacts on other markets than positive ones.

DOI: 10.24818/18423264/53.3.19.17 
Figure 2.Total connectedness with 250-day rolling-sample windows

The result suggests that new shocks occurred in one market can spread to other markets in different degrees, and hence we need to assess the connectedness dynamics as well as the average connectedness over the full sample.

\subsubsection{Cross-country and cross-market connectedness}

Using similar approach to Tables 5 and 6, we can decompose the total connectedness index into within-country and cross-country connectedness. The within-country connectedness indicates the sum of all pairwise connectedness among different asset-class markets (in this study, stock vis-à-vis FX) within the same country. The cross-country connectedness captures the sum of all pairwise connectedness of both the same (e.g., stock vis-à-vis stock) and different asset-class markets across countries. In order to make a direct comparison, we need to adjust the two connectedness measures, as they are derived from different numbers of markets. ${ }^{9}$ Figure 3 presents the decomposition of the total connectedness into the within-country and cross-country connectedness measures, which are 'rescaled' using a similar method to the normalization in equation (4).In this case, the withincountry connectedness is an index representing cross-market (i.e., different assetclass markets) connectedness within each country, while the cross-country connectedness measures include both the same and different asset-class markets across countries.

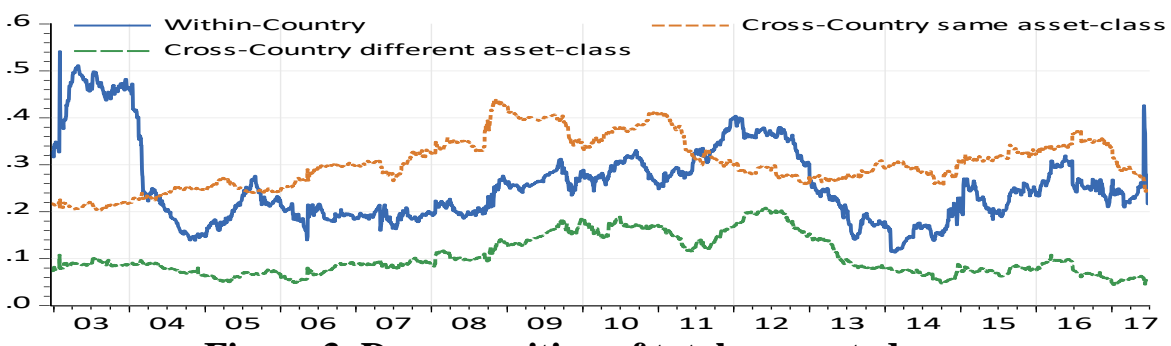

Figure 3. Decomposition of total connectedness

Several interesting observations emerge from the connectedness measures in Figure 3. First, we can clearly see that the within-country connectedness is higher than cross-country different asset-class connectedness during the sample period. Second, the cross-country connectedness for the same asset-class markets is higher than that for different asset-class markets. This indicates that the crosscountry same asset-class markets contribute more to the network connectedness than the cross-country different asset-class markets. Third, the cross-country same

${ }^{9}$ The cross-country connectedness measures are estimated by summing up 84 elements for each same and different asset-class markets, whereas the within-country connectedness measures are estimated by adding 14 elements. 
asset-class connectedness is also higher than the within-country (different assetclass) connectedness for most sample period. This result is consistent with earlier observations that the same asset-class connectedness is stronger than different asset-class connectedness in most financial markets. ${ }^{10}$ As observed for the total connectedness measures in Figure 2, the cross-country same asset-class connectedness also displayed a sharp peak around the GFC, together with subsequent increases during the EDC.

\subsubsection{Cross-region connectedness}

Finally, the directional connectedness measures between advanced and MENA markets are presented in Figure 4, which can be viewed as a dynamic version of Table 6. The directional connectedness measures of US indicate that the US financial markets have affected the MENA markets throughout the sample period, with the highest influence during the GFC. The directional connectedness measures of Euro markets also displayed increasing impacts during the major crises, i.e., the GFC and EDC. Both indices displayed slight increases during 2015 and 2016, with increasing uncertainties concerning raises in the US federal funds rate.
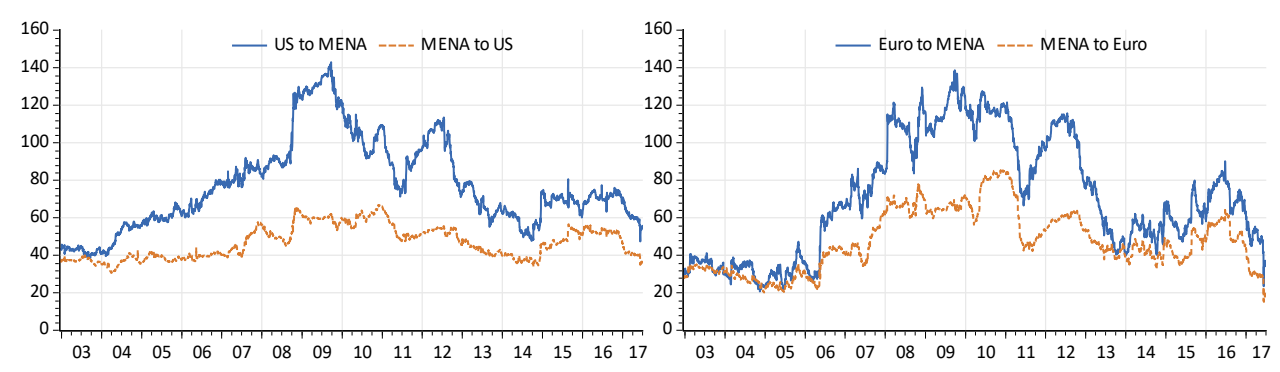

Figure 4. Directional connectedness between advanced and MENA markets

\section{Conclusion}

This paper investigates international linkages among financial markets in the MENA region. In particular, we estimate connectedness measures across different asset-class markets for Egypt, Morocco, Qatar, Saudi Arabia and Turkey. We also discuss the magnitude, direction, and dynamics of the connectedness across various combinations of markets and countries, in relation to US and Euro financial markets.

The basic results can be summarized as follows. The results of full-sample analysis suggest that the connectedness among the MENA countries seems rather weak, while US and Euromarkets are an important source of network effects on financial markets in this region. In particular, the US stock market shows the highest net connectedness, which is consistent with earlier observation on the

\footnotetext{
${ }^{10}$ Using the data on advanced financial markets, Diebold and Yilmaz (2015) suggested that most of the connectedness may take place within the same asset-class markets across countries. Similar results are also presented on the Northeast Asian financial markets in Lee and Lee (2017).
}

DOI: 10.24818/18423264/53.3.19.17 
hierarchy among asset classes in terms of their reflections of the overall economy. Among the MENA countries, Turkey shows the largest 'to' and 'from' connectedness measures in both stock and FX markets. In fact, the Turkish markets show relatively high connectedness with advanced financial markets. The largest pairwise directional connectedness within the MENA region is between the Saudi and Qatari stock markets, which is somewhat expected from their geographical proximity.

The rolling-sample analysis shows that volatility connectedness fluctuates substantially over time, and is very sensitive to economic turmoil. In particular, the total connectedness index has gradually increased since Lehman Brothers bankruptcy in September 2008, until it reached a sharp peak in 2009. The connectedness measures showed subsequent increases during the EDC, evolved from bailouts of Greece in May 2010. This result that the degrees of the connectedness among financial markets are countercyclical is consistent to earlier empirical findings in this area that negative shocks tend to have larger impacts on other markets than positive ones. The observation that new shocks occurred in one market can spread to other markets in different degrees may suggest that we need to assess the connectedness dynamics as well as the average connectedness over the full sample.

When we decompose the total connectedness index into the same and different asset-class markets, we find that the same asset-class connectedness is higher than different asset-class connectedness for most sample period. This result is consistent with earlier observations that the same asset-class connectedness is stronger than different asset-class connectedness in most financial markets.

Overall, the basic findings of our study are consistent with earlier studies, which suggest that the US market is most influential in international financial markets. On the other hand, the connectedness among the MENA markets is quite limited, which also seems to confirm earlier observations on this region. For instance, Neaime (2016) suggests that the MENA stock markets are more linked to advanced economies, whereas their regional integration remains rather weak.

While some interesting observations are presented in this paper, much work still remains to be done. First, the analysis in this study is limited to the stock and FX markets in the MENA region, and hence we need to consider other financial markets as discussed in Lee and Lee (2017). Given that markets for government bonds, corporate bonds and Sukuk in this region have recently been growing very fast, bond markets should be included in the network analysis, as the bond market data become more available. Second, other financial markets in the MENA region (e.g., Bahrain, Oman, Kuwait, and UAE) should also be considered as barriers and restrictions imposed on foreign investments in their domestic equities get lowered in the future.

\section{REFERENCES}

[1] Antonakakis, N. (2012), Exchange Return Co-movements and Volatility Spillovers before and after the Introduction of Euro. Journal of International Financial 
Markets, Institutions \& Money 22, 1091-1109;

[2] Antonakakis, N. and K. Vergos (2013), Sovereign Bond Yield Spillovers in the Euro Zone during the Financial and Debt Crisis. Journal of International Financial Markets, Institutions \& Money 26, 258-272;

[3] Booth, G.G., T. Martikainen and Y. Tse (1997),Price and Volatility Spillovers in Scandinavian Stock Markets. Journal of Banking \& Finance 21, 811-823;

[4] Chang, B.K. (2013), Return and Volatility Spillovers in East Asian Currency Markets A Generalized Variance Decomposition Analysis. Journal of Korea Trade 17, 53-76;

[5] Diebold, F.X. and K. Yilmaz, K. (2012), Better to Give than to Receive: Predictive Directional Measurement of Volatility Spillovers. International Journal of Forecasting 28, 57-66;

[6] Diebold, F. X. and K. Yilmaz (2015), Financial and Macroeconomic Connectedness: A Network Approach to Measurement and Monitoring, Oxford University Press;

[7] Diebold, F.X. and K. Yilmaz (2016),Trans-Atlantic Volatility Connectedness among Financial Institutions: 2004-2014. Journal of Financial Econometrics 14, 81-127;

[8] Eissa, M.A., G. Chortareas and A. Cipollini (2010), Stock Returns and Exchange Rate Volatility Spillovers in the MENA Region. Journal of Emerging Market Finance 9, 257-284;

[9] Eun, C. and S. Shim (1989), International Transmission of Stock Market Movements. Journal of Financial and Quantitative Analysis 24, 241-256;

[10] Garman, M.B. and M.J. Klass (1980),On the Estimation of Security Price Volatilities from Historical Data. Journal of Business 53, 67-78;

[11] Harrathi, N., C. Aloui, M.A. Houfi and J. Majdoub (2016), Emerging Equity Markets Connectedness, Portfolio Hedging Strategies and Effectiveness. International Journal of Financial Research 7, 189-201;

[12] Ibrahim, M.H. (2015), Issues in Islamic Banking and Finance: Islamic Banks, Shari'ah-compliant Investment and Sukuk. Special Section on Islamic Banking and Finance. Pacific-Basin Finance Journal 34, 185-191;

[13] Ibrahim, M.H. and A. Mirakhor (2014),Special Issue on Islamic Banking and Finance. Pacific-Basin Finance Journal 28, 1-190;

[14] Lee, H.S. (2004), International Transmission of Stock Market Movements: A Wavelet Analysis. Applied Economics Letters 11, pp. 197-201;

[15] Lee, H.S. (2010), Price and Volatility Spillovers in MENA Stock Markets. International Area Studies Review 14, 2-29;

[16] Lee, H.S. and W.H. Hong (2009),International Transmission of Swap Market Movements: The US, Korea, and China.Asia-Pacific Journal of Financial Studies 38, 723744

[17] Lee, H.S. and W.S. Lee (2017), International Linkage among Northeast Asian Financial Markets. Working Paper, Department of Economics, Sogang University;

[18] Lee, H.S. and W.S. Lee (2018),Housing Market Volatility Connectedness among G7 Countries. Applied Economics Letters, 146-151;

[19] Liow, K.H. (2014), The Dynamics of Return Co-movements and Volatility Spillover Effects in Greater China Public Property Markets and International Linkages. Journal of Property Investment \& Finance 32, 610-641;

DOI: 10.24818/18423264/53.3.19.17 
Hahn Shik Lee, Woo Suk Lee

[20] Maghyereh, A.I., B. Awartani and K. Al Hilu (2015),Dynamic Transmissions between the U.S. and Equity Markets in the MENA Countries: New Evidence from Preand Post-global Financial Crisis. Quarterly Review of Economics and Finance 56, 123138 ;

[21] Manyika, J. and S. Lund (2014), A Disconnected Middle East. Cairo Review of Global Affairs, online: https://www.thecairoreview.com;

[22] McKinsey Global Institute (2016),Digital Globalization: The New Era of Global Flows. McKinsey \& Company;

[23] Neaime, S. (2016),Financial Crises and Contagion Vulnerability of MENA Stock Markets. Emerging Markets Review 27, 14-35;

[24] Ozturk, S.S. and E. Volkan (2015), Intraindustry Volatility Spillvers in the MENA Region. Emerging Markets Finance \& Trade 51, 1163-1174;

[25] Tsai, I.C. (2014), Spillover of Fear: Evidence from the Stock Markets of Five Developed Countries. International Review of Financial Analysis 33, 281-288;

[26] Yu, J.-S. and M.K. Hassan (2008), Global and Regional Integration of the MENA Stock Markets. Quarterly Review of Economics and Finance 48, 482-504. 